\title{
REVIEW
}

\section{PPAR control: it's SIRTainly as easy as PGC}

\author{
Mary C Sugden, Paul W Caton and Mark J Holness \\ Centre for Diabetes, Queen Mary University of London, Blizard Institute of Cell and Molecular Science, St Bartholomew's and the Royal London School of \\ Medicine and Dentistry, 4 Newark Street, Whitechapel, London E1 2AT, UK \\ (Correspondence should be addressed to M C Sugden; Email: m.c.sugden@qmul.ac.uk)
}

\begin{abstract}
This review describes recent advances in our knowledge of the regulatory interactions influencing the expression of peroxisome proliferator-activated receptor (PPAR)regulated genes. We address recent advances highlighting the role of PPAR $\gamma$ (PPARG) coactivator-1 (PGC-1) and lipin-1 in co-ordinating the expression of genes controlling nutrient handling. We evaluate the possibility that SIRT1 lies at the heart of a regulatory loop involving PPAR $\alpha$, PGC-1 $\alpha$ (PPARA, PPARGC1A as given in the HUGO

Database), and lipin-1 (LPIN1 as listed in the HUGO Database) that ultimately controls the metabolic response to varying nutrient and physiological signals via a common mechanism mediated by post-translation modifications (deacetylation) of both PPAR $\alpha$ and PGC-1s. Finally, we comment on the potential of pharmaceutical manipulation of these targets as well as the possible problems associated with this strategy.

Journal of Endocrinology (2010) 204, 93-104
\end{abstract}

\section{Introduction}

Nuclear receptors (NRs) are members of a superfamily of ligand-regulated and orphan transcription factors that regulate gene expression in response to nutritional and physiological stimuli. NRs are separated into distinct classes. First, there are classic hormone receptors that bind specific hormones, such as the glucocorticoids (GCs), thyroid hormones, and estrogen. The GCs and tri-iodothyronine, acting via the glucocorticoid receptor (GR) and thyroid hormone receptor (TR) respectively, are important regulators of genes involved in metabolic fuel homeostasis during development and in response to metabolic stress. Estrogenrelated receptors (ERRs) also play critical roles in the regulation of cellular energy metabolism. Secondly, there are NRs that function as metabolic sensors, binding to substrate and end-product component molecules of metabolic pathways such as lipids and fatty acids (FA). This second class of NRs includes the peroxisome proliferator-activated receptors (PPARs), liver X receptors (LXRs), the farnesoid $\mathrm{X}$ receptor (FXR), and hepatocyte nuclear factor $4 \alpha$ (HNF- $4 \alpha$ or HNF4A as listed in the HUGO Database) all of which function, together with the retinoid $\mathrm{X}$ receptor (RXR), to regulate lipid and glucose homeostasis in response to nutritional and physiological stimuli.

Importantly, cross-talk can occur between these NRs, for example between ERR and the PPARs, via the common inducible coactivators such as $\operatorname{PPAR} \gamma$ coactivator- $1 \alpha$
(PGC-1 $\alpha$ or PPARGC1A as listed in the HUGO Database). In this review, we focus on how PGC-1s coordinate the regulation of metabolite-responsive NRs and therefore the expression of genes controlling nutrient handling. In particular, we comment on emerging data supporting a common mechanism mediated by post-translation modifications (deacetylation catalyzed by the $\mathrm{NAD}^{+}$-regulated protein deacetylase SIRT) of both PPAR $\alpha$ (PPARA as listed in the HUGO Database) and the PGC-1s, and propose that SIRT1 may lie at the heart of a regulatory loop involving PPARs, PGC-1s, and lipin-1 that ultimately controls the metabolic response of tissues, including liver and adipose tissue, to varying nutrient and physiological signals.

\section{Regulation of the lipo-oxidative NR PPAR $\alpha$ and its role in lipid handling and insulin sensitivity}

Histone acetylation allows trans-acting factors to associate with cognate DNA binding sites and activate transcription. Histone acetyltransferases (HATs) function to acetylate and remodel chromatin, leading to increased access to target genes by transcriptional machinery. In the absence of ligand, PPAR $\alpha$ recruits corepressors and histone deacetylases (HDACs), which reverses histone acetylation, resulting in a more compact chromatin environment in which transcription is repressed (Fig. 1). Activation through ligand binding induces a conformational change leading to dissociation of 


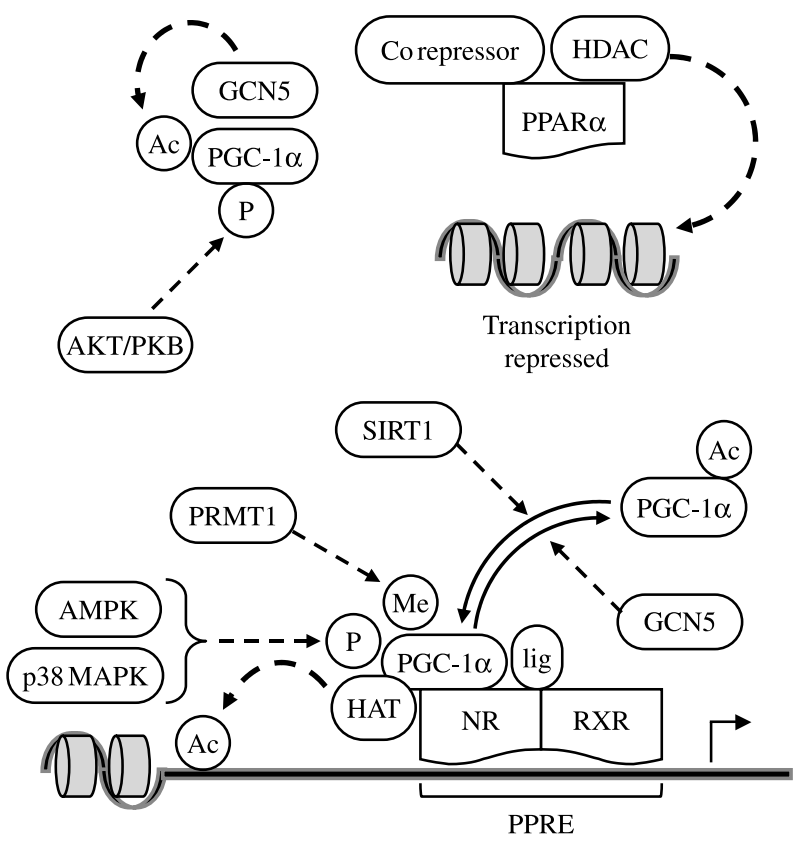

Figure 1 Overview of PGC-1 $\alpha$ post-translational modification. Post-translational modification of PGC- $1 \alpha$ by reversible acetylation, phosphorylation, and methylation are key regulatory factors for PGC-1 $\alpha$ function. SIRT1-mediated deacetylation activates PGC- $1 \alpha$, while acetylation by GCN 5 inhibits PGC- $1 \alpha$-directed gene expression. In skeletal muscle, phosphorylation by AMPK and p38 MAPK increases stabilization of PGC-1 $\alpha$. In contrast, AKT/PKB-mediated phosphorylation facilitates degradation of hepatic PGC-1 $\alpha$. PRMT1 also activates PGC-1 $\alpha$ through methylation at several arginine residues. Ac, acetyl group; AMPK, AMP-dependent protein kinase; HAT, histone acetyl transferase; HDAC, histone deacetylase; MAPK, mitogen-activated protein kinase; Me, methyl group; NR, nuclear receptor; $\mathrm{P}$, phosphate group; PGC- $1 \alpha$, peroxisome proliferator- activated receptor $\gamma$ coactivator $1 \alpha$; PPAR $\alpha$, peroxisome proliferator-activated receptor $\alpha$; PPRE, PPAR response element; PRMT1, protein arginine methyltransferase 1; RXR, retinoid X receptor; SIRT1, sirtuin 2 ortholog 1 .

corepressors and recruitment of protein complexes containing HAT activity that enhance gene transcription via modification of local chromatin structure (Fig. 1). In addition, ligand binding to PPAR $\alpha$ causes $\operatorname{PPAR} \alpha$ to heterodimerize with the RXR and recruit coactivators to activate a program of lipidinduced activation of genes encoding proteins involved in FA uptake, activation, and oxidation. PPAR $\alpha$ target genes include carnitine palmitoyltransferase I (CPT I), involved in the transport of long-chain fatty acyl goups into the mitochondria, medium-chain acyl-CoA dehydrogenase (involved in $\beta$-oxidation) and, specifically in liver, mitochondrial 3-hydroxy-3-methylglutaryl-CoA synthase (the rate limiting enzyme of ketogenesis), peroxisomal acyl-CoA oxidase (peroxisomal $\beta$-oxidation), and microsomal cytochrome P450 (CYP) FA $\omega$-hydroxylases. Thus, PPAR $\alpha$ plays a critical role in maintenance of lipid homeostasis (oxidation and production). Exposure of insulin-sensitive tissues (in particular liver and skeletal muscle) to excess nonesterified FA and circulating triglycerides (triacylglycerol, TAG) induces insulin resistance (Friedman 2002) that can be corrected by the administration of PPAR $\alpha$ activators by actions to promote removal of intracellular lipid through tissue FA oxidation (Ye et al. 2001). Induction of PPAR $\alpha$ gene targets requires the interaction of PPAR $\alpha$ and PGC-1, often in complex with other enzymes and coactivators. Formation of these complexes is required for full transcriptional induction of $\operatorname{PPAR} \alpha$ targets in a variety of tissues.

\section{Regulation of NRs by PGC-1 $\alpha$}

The PGC-1s are a small family of transcriptional coactivators that play a critical role in the control of glucose, lipid, and energy metabolism. There are three known isoforms of PGC-1: PGC-1 $\alpha$ (PPARGC1A); PGC-1 $\beta$ (PPARGC1B); PGC-1-related coactivator (PRC or PPRC1 as listed in the HUGO Database). PGC-1 coactivators functionally interact with transcription factors, in particular with members of the NR superfamily such as PPAR $\gamma$ and PPAR $\alpha$, ERR, LXR, and HNF-4 $\alpha$ (Puigserver \& Spiegelman 2003, Nagai et al. 2009, Yang et al. 2009), but also with non-NR transcription factors and regulatory elements including cAMP response element-binding protein (CREB), the lipogenic transcription factor sterol regulatory element-binding protein-1c (SREBP-1c or SREBF1 as listed in the HUGO Database), and forkhead box O1 (FOXO1), abnormalities in which have been implicated in the development of diabetes (Yamagata et al. 1996, Yoon et al. 2001, Nakae et al. 2002, Puigserver et al. 2003, Gupta et al. 2005).

HAT enzymes such as p300, CBP, and SRC-1 bind to the amino terminal of PGC-1, where they function to acetylate and remodel chromatin, leading to modified access to target genes by transcriptional machinery (Fig. 1). The carboxy terminus of PGC-1 contains a Ser/Arg-rich region, an RNA binding domain which is involved in RNA processing, and is bound by TRAP/DRIP, a modulating complex involved in transcriptional initiation. NRs including the PPARs, ERR, HNF-4 $\alpha$ and GR commonly bind to LXXLL motifs present in the $\mathrm{N}$-terminal domain, while other transcription factors bind to different regions of the protein. This allows for a coordinated transcriptional response to nutrient and physiological signals.

All three isoforms of PGC-1 play a common role in control of mitochondrial physiology and FA oxidation, but also regulate differing metabolic pathways in an isoform-specific manner. PGC- $1 \alpha$ and PGC- $1 \beta$ are highly expressed in tissues dependent on aerobic metabolism such as heart, skeletal muscle, and brown adipose tissue, where they coactivate nuclear respiratory factors (NRFs). In turn, the NRFs induce expression of genes that regulate mitochondrial DNA and function and induce mitochondrial biogenesis.

\section{Post-translational modification of PGC- $1 \alpha$}

PGC-1 coactivators have the ability to regulate their own transcription in response to nutrient signaling such as fasting/fed status. However, an extra level of regulation is 
exerted through post-translational modifications. In particular, reversible acetylation, phosphorylation, and methylation are key mechanisms by which PGC- $1 \alpha$ function is maintained (Fig. 1). Both PGC- $1 \alpha$ and PGC- $1 \beta$ are found in complex with GCN5, an acetyl transferase which acetylates PGC-1 at several lysine residues and inhibits its transcriptional activity (Lerin et al. 2006; Fig. 1). Conversely, protein deacetylase SIRT1 (the mammalian Sir2 ortholog) deacetylates a number of nonhistone targets including PGC- $1 \alpha$ and PGC- $1 \beta$, with activation of both cofactors (Rodgers et al. 2005, Kelly et al. 2009; Fig. 1). Thus, SIRT1 opposes the action of GCN5 and induces expression of PGC-1 gene targets (Rodgers et al. 2005, Kelly et al. 2009; Fig. 1). SIRT1, located in the cell nucleus, requires $\mathrm{NAD}^{+}$as a cofactor and is negatively regulated by either NADH or the deacetylation product nicotinamide. SIRT1 consumes one $\mathrm{NAD}^{+}$for every acetyl group removed from a protein substrate. A decrease in the $\mathrm{NAD}^{+} / \mathrm{NADH}$ ratio inhibits SIRT1 activity. This dependency on oxidized NAD may link SIRT1 activity to cellular metabolism.

Another level of complexity is introduced since, in muscle, PGC- $1 \alpha$ is phosphorylated by both p38 MAPK and the energy-sensing enzyme, AMP-activated protein kinase, leading to a more stable and active protein (Puigserver et al. 2001, Irrcher et al. 2009; Fig. 1). In contrast, phosphorylation of PGC- $1 \alpha$ by AKT/protein kinase B (involved in the insulin signaling cascade) in the liver leads to decreased stability and activity (Li et al. 2007a; Fig. 1). Furthermore, PGC-1 $\alpha$ function is induced through methylation at several arginine residues in the $\mathrm{C}$-terminal region by protein arginine methyltransferase I (PRMT1; Fig. 1), which also coactivates NRs (Teyssier et al. 2005). Of interest, nonobese diabetic Goto-Kakizaki rats, a rodent model of diabetes, have decreased hepatic PRMT activity associated with impaired arginine methylation, and transfection with PRMT siRNA attenuates insulin signaling to gluconeogenic gene expression (Iwasaki 2009). Thus, control of PPAR $\alpha-P G C-1 \alpha$ gene transcription is emerging as a complex regulatory platform consisting of other NRs, various factors that amplify the signal and confer stability on the key transcription factors and cofactors, all of which appear to be necessary for full transcriptional induction of PPAR $\alpha$ gene targets.

\section{SIRT1 as a regulator of PPAR $\alpha-$ PGC- $1 \alpha$ directed gene expression in liver}

Expression of PGC-1 coactivators in the liver is relatively low in the fed state; however, in parallel with effects of fasting to increase PPAR $\alpha$ signaling, hepatic PGC-1 $\alpha$ mRNA expression is elevated after starvation (Herzig et al. 2001, Yoon et al. 2001) and plays a critical role in the regulation of hepatic gluconeogenesis (Fig. 2) and FA oxidation. Importantly, $P g c-1 \alpha$ mRNA expression is also increased in three different rodent models of increased hepatic gluconeogenesis (Herzig et al. 2001, Yoon et al. 2001). Increased expression of PGC- $1 \alpha$ in liver via adenovirus vector enhances hepatic

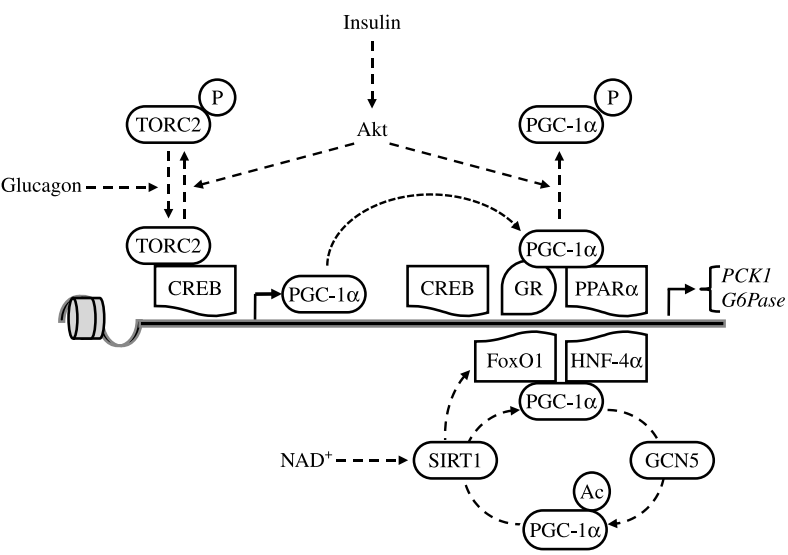

Figure 2 The critical role of PGC- $1 \alpha$ in the regulation of hepatic gluconeogenesis. Glucagon stimulates the dephosphorylation and translocation of the CREB-regulated transcriptional coactivator (TORC2) to the nucleus, where it coactivates CREB leading to induction of PGC- $1 \alpha$. PGC- $1 \alpha$ subsequently coactivates and forms complexes with FoxO1, the GR and HNF-4 $\alpha$ (as well as PPAR $\alpha$ ) and induction of gluconeogenic gene expression. Activation of Akt by insulin phosphorylates TORC2 and PGC- $1 \alpha$ leading to their degradation. PGC $-1 \alpha$ is deacetylated by SIRT1, induction of PGC- $1 \alpha$ being associated with coactivation of FoxO1 and HNF-4 $\alpha$ and induction of gluconeogenic gene expression. This PGC- $1 \alpha$-directed gluconeogenic gene expression pathway is inhibited by GCN5. Ac, acetyl group; CREB, CAMP response element-binding protein; FoxO1, forkhead box O1; GR, glucocorticoid receptor; HNF- $4 \alpha$, hepatocyte nuclear factor- $4 \alpha$; P, phosphate group; PGC- $1 \alpha$, peroxisome proliferator-activated receptor $\gamma$ coactivator $1 \alpha$; $\operatorname{PPAR} \alpha$, peroxisome proliferator-activated receptor $\alpha$; SIRT1, sirtuin 2 ortholog 1 ; TORC2, CREB-regulated transcriptional coactivator 2.

glucose production (Herzig et al. 2001; reviewed in Vidal-Puig \& O'Rahilly (2001)). The rise in glucagon levels on fasting is associated with the dephosphorylation and translocation of the CREB-regulated transcription coactivator (TORC2 that is listed as CRTC2 in the HUGO Database) to the nucleus, where it coactivates CREB, a transcription factor present on the PGC- $1 \alpha$ gene promoter, leading to induction of PGC- $1 \alpha$ (Fig. 2). PGC- $1 \alpha$ subsequently coactivates and forms complexes with FoxO1, the GR and HNF- $4 \alpha$, which (as well as PPAR $\alpha$ ) are essential for expression of the key gluconeogenic genes PCK1 and/or G6Pase (Fig. 2). Conversely, activation of AKT by insulin elicits phosphorylation of both TORC2 and PGC- $1 \alpha$ leading to their degradation (Dentin et al. 2007, Li et al. 2007a).

An alternative gluconeogenic pathway has been described, where PGC- $1 \alpha$ is deacetylated by SIRT1, induction of PGC- $1 \alpha$ being associated with coactivation of FOXO1 and HNF- $4 \alpha$ and induction of gluconeogenic gene expression (Rodgers et al. 2005; Fig. 2). SIRT1 also opposes phosphorylation-dependent nuclear exclusion of FOXO1 and elicits translocation and restriction of FoxO1 to a nuclear subdomain in hepatocytes (Frescas et al. 2005). Interestingly, this pathway was not activated by classical gluconeogenic stimuli, including the GCs and glucagon, and is thought to represent an entirely separate parallel pathway for induction 
of gluconeogenic gene expression (Rodgers et al. 2005), which may involve a rise in pyruvate and $\mathrm{NAD}^{+}$levels (reviewed in Rodgers et al. (2008)). This PGC-1 $\alpha$-directed gluconeogenic gene expression pathway is inhibited by GCN5 (Lerin et al. 2006).

Studies of the role of PGC- $1 \alpha$ on energy metabolism have mainly utilized gain-of-function or complete-loss-of-function models. Total ablation of hepatic PGC- $1 \alpha$ elicits fasting steatosis; however, insulin sensitivity and glucose tolerance are improved concomitant with suppression of gluconoegenesis. However, this phenotype may reflect consequences of loss of PGC- $1 \alpha$ function in nonhepatic tissues, including skeletal muscle, heart, brain, and brown fat that elicit abnormal heart function, muscle performance, and thermogenesis (Lin et al. 2004, Leone et al. 2005). In contrast, a recent study has examined the long-term metabolic impact of physiological changes in PGC- $1 \alpha$ expression, achieved using a Cre/Lox system to create mice heterozygous for PGC- $1 \alpha$ specifically within the liver (Estall et al. 2009). Loss of one allele of hepatic PGC- $1 \alpha$ led to a chronic reduction in hepatic PGC- $1 \alpha$ mRNA and protein (Estall et al. 2009). This resulted in impaired FA oxidation and TAG assembly and/or production pathways leading to hypertriglyceridemia (Estall et al. 2009). In addition these mice exhibited reduced hepatic insulin sensitivity, which was associated with impaired insulinstimulated Akt activation (Estall et al. 2009). Nevertheless, the long-term decline in PGC- $1 \alpha$ led to only a modest reduction in gluconeogenesis (Estall et al. 2009). Interestingly, acute disruption of hepatic PGC-1 expression using an RNAi adenovirus has opposing effects, leading to enhanced insulin sensitivity, in part reflecting reduced expression of the mammalian tribbles homolog TRIB3 (Koo et al. 2004), an inhibitor of AKT signaling (Mortensen et al. 2006). These mice were characterized by fasting hypoglycemia and reduced expression of PEPCK and G6Pase (Koo et al. 2004).

Recently, SIRT1-mediated deacetylation of PGC-1 $\alpha$ has been reported to play a critical role in regulation of hepatic FA oxidation. Hepatic deletion of SIRT1 leads to impaired $\operatorname{PPAR} \alpha$ signaling, while overexpression of SIRT1 activates PPAR $\alpha$, increasing expression of PPAR $\alpha$ gene targets. SIRT1 induces PPAR $\alpha$ signaling through deacetylation of PGC- $1 \alpha$ (Purushotham et al. 2009; Fig. 3). Interestingly, SIRT1 does not affect the formation of the PPAR $\alpha-\mathrm{PGC}-1 \alpha$ complex, since in SIRT1 knockdown hepatocytes PGC-1 $\alpha$ is still recruited to the PPAR response element (PPRE) of FA oxidation genes. However, PGC $-1 \alpha$ remains acetylated when SIRT1 is not present so it is unable to induce transcription of PPAR $\alpha$ gene targets. There is a potential inhibitory role for GCN5 in this system. As noted above, GCN5 counters the effect of SIRT1 by acetylating PGC1 $\alpha$, inhibiting its transcriptional activity (Lerin et al. 2006, Gerhart-Hines et al. 2007; Fig. 3). Hence, the balance between relative levels and activity of SIRT1 and GCN5 could provide regulatory convergence point for induction of PPAR $\alpha$ gene targets. In agreement, PGC- $1 \alpha$ target genes for FA oxidation are induced in skeletal muscle by SIRT1 and inhibited by GCN5 (Gerhart-Hines et al. 2007).

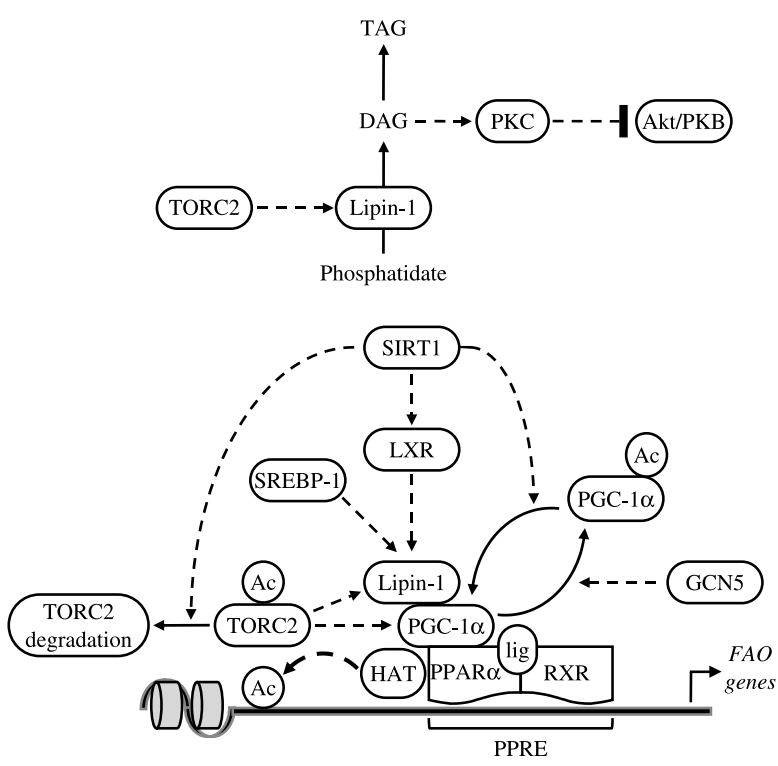

Figure 3 Overview of lipin-1 regulation of PGC1 $\alpha-P P A R \alpha$-directed gene expression. Lipin-1 is reported to enhance PPAR $\alpha-$ PGC- $1 \alpha$ directed gene expression through induction of PPAR $\alpha$ transcription and by forming a complex with PGC- $1 \alpha$ and PPAR $\alpha$, leading to increased FA oxidation. In contrast, TORC2-mediated induction of lipin-1 leads to increased DAG and TAG synthesis. Ac, acetyl group; AMPK, AMP-dependent protein kinase; DAG, diacylglycerol; FAO, fatty acid oxidation; HAT, histone acetyl transferase; LXR, liver X receptor; PGC-1 $\alpha$, peroxisome proliferator-activated receptor $\gamma$ coactivator $1 \alpha$; PKC, protein kinase C; PPAR $\alpha$, peroxisome proliferator-activated receptor $\alpha$; PPRE, PPAR response element; $\mathrm{RXR}$, retinoid X receptor; SIRT1, sirtuin 2 ortholog 1; SREBP-1, sterol regulatory element binding protein 1; TAG, triacylglycerol; TORC2, CREB-regulated transcriptional coactivator 2.

While this study did not examine GCN5 or PPAR $\alpha$ directly, it seems likely that both GCN5 and SIRT1 are part of the same regulatory platform of PPAR $\alpha-\mathrm{PGC} 1 \alpha$ induction of FA oxidation in skeletal muscle, liver, and other metabolically active tissues. These may include pancreatic islets, linking insulin secretion with insulin action in liver and skeletal muscle. This seems particularly likely since both $\operatorname{PPAR} \alpha$ and SIRT1 have been separately reported to repress a common gene target, uncoupling protein 2 (UCP2) that plays an important role in regulation of insulin secretion (Bordone et al. 2006, Ramsey et al. 2008).

\section{Lipin-1 as a coordinator of PPAR $\alpha-$ PGC-1 $\alpha$ - directed gene expression}

Lipin-1 (listed as in LPIN1 in the HUGO Database) is another regulator of PPAR $\alpha-P G C-1 \alpha$-directed gene expression. In the cytoplasm, lipin-1 promotes TAG accumulation and phospholipid synthesis by functioning as a $\mathrm{Mg}^{2+}$-dependent phosphatidate phosphatase (phosphatidic acid phosphatase-1 (PAP-1); Reue \& Zhang 2008; Fig. 3). PAP-1 converts phosphatidate to diacylglycerol (DAG), the immediate precursor of TAG and neutral phospholipids. 
The expression level and compartmentalization of lipin-1 controls the assembly and secretion of hepatic very lowdensity lipoprotein (VLDL; Bou Khalil et al. 2009). Overexpression of lipin-1 in cultured hepatocytes leads to increased TAG synthesis (Bou Khalil et al. 2009). In the nucleus, lipin-1 acts as a transcriptional coativator linked to FA oxidation (Fig. 3). The role of lipin-1 in transcriptional activation was discovered in a mouse model of PGC- $1 \alpha$ deficiency, in which fasting failed to induce the hepatic expression of lipin-1, PPAR $\alpha$, and PPAR $\alpha$ target genes involved in upregulation of FA oxidation (Finck et al. 2006). Subsequently, lipin-1 has emerged as an important regulatory factor for induction of PPAR $\alpha-P G C-1 \alpha$ gene targets. Lipin1 induces PPAR $\alpha$ gene expression as well as forming an interactive complex with PPAR $\alpha$ and PGC- $1 \alpha$ (Fig. 3) leading to induction of FA oxidation genes including CPT1 (Finck et al. 2006). Conversely, a mutation in lipin-1 is responsible for the fatty liver dystrophic $(f l d)$ mouse phenotype, which includes hepatic steatosis, impaired FA oxidation, and hyperlipidemia (Reue 2009). Lipin-1 can also interact with other hepatic transcription factors such as HNF$4 \alpha, \operatorname{PPAR} \delta$ and PPAR $\gamma$, indicating that lipin-1 and PGC- $1 \alpha$ may act as a regulatory link between PPAR $\alpha$ and other NRs. Of interest, it has been reported recently that the lipogenic transcription factor SREBP-1 is involved in the regulation of lipin-1 expression (Fig. 3) and that lipin-1 protein is induced by sterol depletion (Ishimoto et al. 2009). In addition, lipin-1 gene expression is induced by T0901317, an activating ligand for the LXR (Ishimoto et al. 2009).

A further layer of complexity in lipin-1 function is highlighted by recent studies detailing a role of lipin-1 in the development of insulin resistance that conflicts with the beneficial effects of lipin-1 through amplification of the PPAR $\alpha-P G C-1 \alpha$ signaling pathway. Lipin-1 is induced by TORC2 (Ryu et al. 2009), a key coactivator of gluconeogenic gene expression (Koo et al. 2005; Fig. 3), which leads to increased levels of DAG and consequent activation of protein kinase C. This, in turn, leads to inhibition of Akt signaling and insulin resistance (Fig. 3). TORC2 also induces PGC-1 $\alpha$ (Koo et al. 2005; Fig. 3), while knockdown of lipin-1 decreases PGC-1 $\alpha$ mRNA levels (Ryu et al. 2009). Interestingly, SIRT1 has been reported to deacetylate TORC2 leading to its ubiquitin-mediated degradation and inhibition of gluconeogenic gene expression (Liu et al. 2008; Fig. 3). However, the impact of SIRT1 on TORC2-mediated lipin induction has yet to be characterized.

Given that SIRT1 is able to induce degradation of TORC2 as well as activating PGC- $1 \alpha$, it seems possible that SIRT1 lies at the heart of a regulatory loop involving $\operatorname{PPAR} \alpha, \operatorname{PGC}-1 \alpha$, lipin-1, and TORC2 (Fig. 3) that ultimately controls the response of lipid metabolism in the liver, and potentially other tissues, to different nutrient and physiological signals. Further credence is added to this hypothesis given reports that SIRT1 acts on targets in a signal-specific manner, deacetylating PGC-1 $\alpha$ only in response to nutrient signaling but not glucagon (Rodgers et al. 2005, 2008). Hence, in healthy individuals, in response to a high-fat diet, SIRT1 may stimulate FA oxidation through PPAR $\alpha-$ PGC- $1 \alpha-$ lipin- 1 . This process may be countered by GCN5-directed acetylation of PGC-1 $\alpha$. In contrast, when the body requires synthesis of TAG an alternative signaling mechanism would induce a TORC2-mediated increase in lipin-1, leading to increased TAG production.

\section{The SIRT1-PGC-1 $\alpha$ axis and lipin-1 signaling to glucose-stimulated insulin secretion}

Normal pancreatic islets express both PGC-1 $\alpha$ (Yoon et al. 2003) and SIRT1 (Moynihan et al. 2005) at low levels. As in liver, fasting for $24 \mathrm{~h}$ increases PGC- $1 \alpha$ mRNA expression in islets, an effect reversed by $24 \mathrm{~h}$ of refeeding (Zhang et al. 2005). More importantly, PGC-1 $\alpha$ mRNA and protein expression have been reported to be elevated in islets from animal models of diabetes, including the $o b / o b$ mouse and ZDF rats (Yoon et al. 2003). Overexpression of PGC- $1 \alpha$ in islets substantially reduces the expression of the $\beta$-cell glucose sensors for glucose-stimulated insulin secretion (GSIS), GLUT2, and glucokinase, and also impairs GSIS, suggesting it can precipitate $\beta$-cell dysfunction (Yoon et al. 2003). Chronic hyperlipidemia and hyperglycemia, which together cause adverse effects on $\beta$-cell function via 'glucolipotoxicity' (reviewed in Nolan \& Prentki (2008)), also affect PGC-1 $\alpha$ gene expression. Islets incubated with oleate/palmitate for $72 \mathrm{~h}$ show a dose-dependent increase in PGC- $1 \alpha \mathrm{mRNA}$ expression, whereas inhibition of $P G C-1 \alpha$ by siRNA improves the impairment of GSIS induced by chronic exposure to FA (De Souza et al. 2003, 2005, Zhang et al. 2005). This suggests that enhanced PGC- $1 \alpha$ expression participates in chronic hyperlipidemia-induced $\beta$-cell failure. However, exposure to high $(25 \mathrm{mM})$ glucose (which also impairs insulin secretion) suppresses PGC- $1 \alpha$ mRNA expression (Zhang et al. 2005). When exposed to high glucose and FA in combination, the effect of hyperglycemia to lower PGC-1 $\alpha$ in islets was dominant (Zhang et al. 2005). If PCG-1 expression limits PPAR $\alpha$ transcriptional activity, this might explain why $\operatorname{PPAR} \alpha$ null mice maintained on standard lowcarbohydrate diet have no obvious phenotype, including unaltered GSIS (Bihan et al. 2005). Suppression of PCG-1 $\alpha$ expression by hyperglycemia could become maladaptive if the islets are simultaneously exposed to high lipids or where increased dietary lipid delivery is sustained over a long period.

Analogs of the incretin GLP-1 (listed as ZGLP1 in the HUGO Database) have been proposed as a possible means to enhance islet function in type 2 diabetes (Nielsen 2005). However, GLP-1 increases islet PGC-1 $\alpha$ mRNA expression (Zhang et al. 2005) which, as noted above, leads to repression of genes involved in $\beta$-cell glucose sensing with a marked inhibition of GSIS (Yoon et al. 2003). Increased SIRT1 expression specifically in pancreatic $\beta$ cells (BESTO transgenic mice), which would be predicted to induce PPAR $\alpha$ signaling through deacetylation and induction of PGC- $1 \alpha$ improves glucose tolerance and enhances insulin secretion, in particular 
first-phase insulin secretion, in response to glucose and the plasma membrane-depolarizing agent $\mathrm{KCl}$ (Moynihan et al. 2005). Microarray analyses of MIN6 cells overexpressing SIRT1 identified 41 downregulated and 24 upregulated transcripts, while analysis of MIN6 cell lines constitutively expressing siRNAs against the Sirt1 gene revealed 24 upregulated and 18 downregulated transcripts (Moynihan et al. 2005). In particular, the expression of Ucp2 and the prolactin receptor gene $(P r l r)$, both of which significantly influence $\beta$-cell function, were downregulated by SIRT1 overexpression (Moynihan et al. 2005). Downregulation of UCPs is proposed to reduce uncoupling and allow a more efficient ATP production under circumstances of limited access to nutrients, which could be explained by a more efficient oxidative phosphorylation, lowered production of ROS, and reduced oxidative damage.

GCs induce lipin-1 in differentiating adipocytes, and a GC response element (GRE) has been identified in the Lpin1 promoter (Zhang et al. 2008). We demonstrated that excessive exposure to the synthetic GC dexamethasone during the last third of pregnancy both causes insulin resistance and impairs islet adaptations to insulin resistance with a complex interaction between GC and PPAR $\alpha$ signaling (Holness \& Sugden 2001, Holness et al. 2006). Thus, the strong possibility exists that lipin-1, if expressed and functional in islets, may exert a coactivator function whereby, via its physical interactions with PPAR $\alpha$ and the GC receptor, is very likely to impact GSIS. The potential importance of the GC in regulating lipin-1 expression in adipose tissue may therefore extend to regulating lipin-1 expression or function in the pancreatic islet.

\section{The lipogenic NRs (the LXR and PGC-1 $\beta$, PPAR $\gamma$ )}

\section{LXR's roles in liver and white adipose tissue: a role for SIRT1}

LXRs $\alpha$ and $\beta$, like the PPARs, are a second family of nutrientreponsive NRs that heterodimerize with $\mathrm{RXR}$ to influence gene expression. LXR $\beta$ (NR1H2) is ubiquitously expressed. $\mathrm{LXR} \alpha(\mathrm{NR} 1 \mathrm{H} 3)$ is abundant in liver and also in adipose tissue, intestine, kidney, and spleen. LXR activation is thought to be predominantly insulin-sensitizing (Cao et al. 2003, Dalen et al. 2003, Laffitte et al. 2003) due to suppression of hepatic glucose output secondary to an LXR-led reduction in gluconeogenic capacity (Stulnig et al. 2002a,b). However, the LXRs also promote hepatic lipid synthesis and can elicit dramatic increases in hepatic TAG production (Tobin et al. 2002, Chen et al. 2004). Thus, as well as acting as sensors of cellular cholesterol and modulating the expression of genes concerned with cellular cholesterol handling, the LXRs enhance expression of genes involved in FA biosynthesis and TAG secretion.

As in liver, LXR activation in adipocytes stimulates lipid accumulation (Juvet et al. 2003). LXR $\alpha$ gene expression is increased in adipose tissue from obese human subjects (Dahlman et al. 2006), whereas LXR-deficient mice show increased FA synthesis and energy consumption (Kalaany et al. 2005). In addition to their conventional role in storing TAG, adipocytes contain large amounts of free cholesterol, and constitute the body's largest pool of free cholesterol (Krause \& Hartman 1984). It has been proposed that adipose tissue acts as a cholesterol sink and cholesterol acts to signal a requirement for adipocyte hypertrophy and/or serve as a sensor of adipocyte TAG storage (Le Lay et al. 2001, 2003). PPAR $\alpha$ null mice have a markedly higher plasma cholesterol content (Patel et al. 2001, Knight et al. 2003), suggesting that, although expressed at relatively low level in adipose tissue, PPAR $\alpha$ is involved in the regulation of adipocyte cholesterol 'buffering'.

LXR increases the synthesis of FA and TAG by upregulating SREBP-1c (Repa et al. 2000). A carbohydrate response element-binding protein (ChREBP that is listed as MLXIPL in the HUGO Database), a glucose-sensitive transcription factor that enhances hepatic conversion of excess carbohydrate to lipid (Yamashita et al. 2001), is a hepatic LXR target which stimulates lipogenic genes independent of SREBP-1c (Cha \& Repa 2007). It has been proposed that, in liver, glucose at physiological concentrations is a highaffinity LXR ligand (Mitro et al. 2007). This may explain why both low-fat and high-carbohydrate diets can induce hypertriglyceridemia. The lipogenic actions of the LXRs directly oppose the action of $\operatorname{PPAR} \alpha$, which promotes FA oxidation (reviewed in Mandard et al. (2004)). It has been suggested that PPARs suppress SREBP-1c promoter activity through inhibition of LXR signaling (Yoshikawa et al. 2003).

LXRs are acetylated at Lys ${ }^{432}$ in $\operatorname{LXR} \alpha$ and $\mathrm{Lys}^{433}$ in LXR $\beta$, and deacetylation regulates LXR transcriptional activity (Li et al. 2007b). LXR agonists trigger deacetylation as SIRT1 interacts with LXR in a ligand-dependent manner (Li et al. 2007b). It appears that, as acetylation of Lys ${ }^{432}$ prevents LXR ubiquitination, LXR is hypo-ubiquitinated (and therefore stabilized) in the absence of SIRT. This stabilization of LXR lowers its transcriptional activity, which explains why LXR activity is lower in the absence of SIRT1. SIRT1 deacetylates and thus positively regulates LXR (Fig. 3).

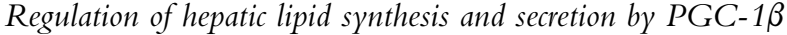

Although PGC-1 was originally reported to combine with the lipogenic PPAR, PPAR $\gamma$, it is now clear that PGC-1 $\beta$ (PPARGC1B) can influence lipid synthesis by acting on a range of transcription factors. Thus, PGC- $1 \beta$ plays a critical role in stimulating the expression of genes involved in hepatic lipogenesis and TAG secretion. Adenoviral-mediated overexpression of hepatic PGC- $1 \beta$ in rats leads to increased TAG synthesis and VLDL secretion and consequent hypertriglyceridemia and hypercholesterolemia (Lin et al. 2005). PGC-1 $\beta$ induces hepatic lipogenesis through coactivation of both LXR and SREBP-1 (Lin et al. 2005). This leads to increased expression of the lipogenic genes FA synthase (FAS), stearoylCoA desaturase (SCD1) and HMG-CoA reductase (HMGCR; Fig. 4). Both PGC-1 $\beta$ and SREBP-1c, but not 


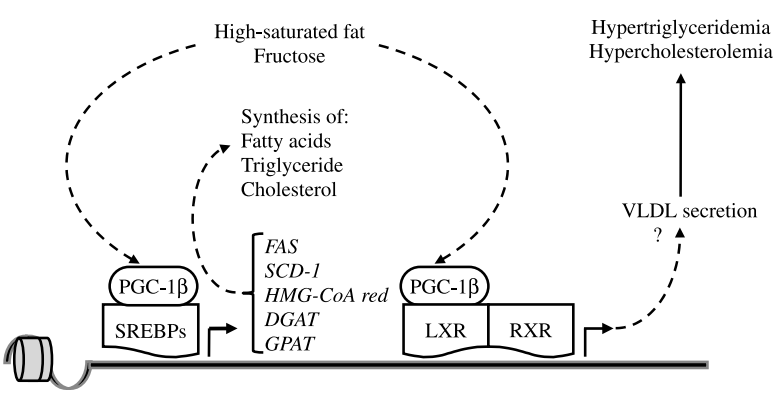

Figure 4 The critical role of PGC- $1 \beta$ in stimulating hepatic lipid synthesis and secretion. PGC-1 $\beta$ is induced in liver in response to high dietary saturated fat and fructose. PGC- $1 \beta$ coactivates SREBP-1C and increases the expression of a range of genes involved in the synthesis of FA, TAG and cholesterol, including FAS, SCD-1, HMG-CoA reductase, DGAT and GPAT. PGC- $1 \beta$ also stimulates VLDL secretion, possibly via augmenting activation of $L X R \alpha$, leading to hypertriglyceridemia and accumulation of cholesterol in VLDL, the precursor to LDL cholesterol. LXR, liver $X$ receptor; PGC-1 $\beta$, peroxisome proliferator-activated receptor $\gamma$ coactivator $1 \beta$; RXR, retinoid $X$ receptor; SREBP, sterol regulatory elementbinding protein; $\mathrm{VLDL}$, very low-density lipoprotein; ?, indicates potential mechanism.

PGC-1 $\alpha$, are induced in liver in response to acute $(24-48 \mathrm{~h})$ high $(58 \%)$ dietary saturated fat (mainly hydrogenated coconut oil; Fig. 4). Interestingly, the increases in PGC-1 $\beta$ and SREBP-1c in response to dietary saturated fat were specific to liver and not replicated in skeletal muscle or white adipose tissue, while dietary cholesterol intake had little impact on hepatic PGC-1 $\beta$ expression (Lin et al. 2005). PGC-1 $\beta$ coactivates SREBP-1c and increases the expression of a range of genes involved in the synthesis of FA, TAG and cholesterol, including FAS, SCD-1, HMGCR, DGAT, GPAT, and microsomal triglyceride transfer protein (MTTP; Lin et al. 2005; Fig. 4). While SREBP overexpression alone increases lipogenic gene expression and heptic lipid levels (Shimano et al. 1996, Horton et al. 1998), hypertriglyceridemia does not occur, probably as a result of parallel upregulation of hepatic low-density lipoprotein receptor (LDLR) levels (Shimano et al. 1997). In contrast, PGC-1 $\beta$ fails to stimulate LDLR expression, but does stimulate VLDL secretion, possibly via augmenting activation of $\operatorname{LXR} \alpha$, leading to hypertriglyceridemia and accumulation of cholesterol in VLDL, the precursor to LDL cholesterol (Lin et al. 2005; Fig. 4).

More recently, antisense oligonucleotide-mediated knockdown of hepatic PGC-1 $\beta$ has been demonstrated to oppose the lipogenic impact of a high-fructose diet (Nagai et al. 2009). Knockdown of PGC-1 $\beta$ was associated with attenuation of fructose-induced increases in SREBP-1c, LXR, and FAS expression (Nagai et al. 2009). Thus, PGC$1 \beta$ has been suggested as a novel mechanism linking the consumption of saturated fat to hypertriglyceridemia and hypercholesterolemia (Lin et al. 2005; Fig. 4). Upregulation of PGC-1 $\beta$ may represent the mechanism linking excessive intake of saturated fat or fructose to hyperlipidemia, insulin resistance and atherosclerosis.
PPAR $\gamma$ and adipocyte function: interactions with SIRT1 and lipin-1

PPAR $\gamma$ activation promotes lipid synthesis and storage in white adipose tisue (Kubota et al. 1999), as well as preadipocyte differentiation to mature adipocytes (Park et al. $2008)$. Wnt/ $\beta$-catenin signaling maintains preadipocytes in an undifferentiated state in part through inhibition of PPAR $\gamma$ (Prestwich \& Macdougald 2007). Rev-erb $\alpha$ acts downstream of PPAR $\gamma$ by facilitating gene expression of PPAR $\gamma$ target genes, including that encoding $\mathrm{C} / \mathrm{EBP} \alpha$ (important for the acquisition of insulin sensitivity; Wu et al. 1999, Rosen et al. 2000) and acts as a repressor of anti-adipogenic genes. $\operatorname{PPAR} \delta$, also expressed in adipose tissue, is not involved in preadipocyte differentiation directly, but is implicated in the control of preadipocyte proliferation and PPAR $\gamma$ gene expression (reviewed in Grimaldi (2001)).

Certain PPAR $\gamma$ target genes that are normally expressed only at low levels in mature adipocytes are dramatically upregulated by thiazolidinediones (TZDs), among these the enzyme glycerol kinase. Glycerol kinase allows glycerol 3-phosphate production from glycerol, thereby enhancing the capacity for FA esterification to TAG. Unlike classic $\operatorname{PPAR} \gamma$-target genes such as aP2 (which is constitutively associated with coactivators), the glycerol kinase gene is targeted by NR corepressors. TZDs trigger the dismissal of corepressor HDAC complexes and the recruitment of coactivators to the glycerol kinase gene. They also induce PGC-1 $\alpha$, whose recruitment to the glycerol kinase gene is sufficient to release the corepressors (Guan et al. 2005). Ectopic expression of PGC- $1 \alpha$ in white adipocytes increases the expression of UCP1, genes encoding respiratory chain proteins (cytochrome $c$-oxidase subunits COX II and IV) and enzymes of FA oxidation and causes white adipocytes to acquire features of brown adipocytes (Puigserver et al. 1998, Tiraby et al. 2003). In ob/ob mice, the expression of transcripts encoding mitochondrial proteins decreases with the development of obesity. TZD treatment in $o b / o b$ mice increases PGC- $1 \alpha$ expression and increases mitochondrial mass and energy expenditure. In mature adipocytes, SIRT1 binds and represses PPAR $\gamma$ in association with mobilization of fat stores during food deprivation (Picard et al. 2004). In contrast, lipin-1 promotes adipocyte TAG storage (see above). Lipin-1 physically interacts with PPAR $\gamma$ and is recruited to PPAR $\gamma$ response element upstream of the PEP carboxykinase (PEPCK) gene (Koh et al. 2008). PEPCK is involved in glycerogenesis in white adipose tissue (Franckhauser et al. 2002).

Lipin-1 deficiency in fld mice causes lipodystrophy characterized by impaired adipose tissue development (Reue et al. 2000). Lipin-1 overexpression in adipocytes promotes increased TAG content and obesity (Phan \& Reue 2005). In the mouse, lipin-1 deficiency is associated with insulin resistance, whereas transgenic overexpression of lipin-1 in adipose tissue promotes insulin sensitivity, even though the mice have increased adiposity (Phan \& Reue 2005). 
High adipose tissue lipin-1 expression is also associated with enhanced insulin sensitivity in man (Yao-Borengasser et al. 2006, Miranda et al. 2007, Donkor et al. 2008). This enhanced insulin sensitivity may reflect an increased ability of adipose tissue to act as a sink for lipid, preventing excessive lipid deposition in liver and skeletal muscles which impairs insulin action.

\section{Clinical implications}

Targetting PPAR $\alpha$-activated genes has been proposed to be beneficial for countering fatty liver (Purushotham et al. 2009), while increasing PGC-1 $\alpha$ protects against the development of insulin resistance in skeletal muscle through induction of GLUT4, increased FA oxidation and mitochondrial biogenesis (Michael et al. 2001, Lagouge et al. 2006, Gerhart-Hines et al. 2007, Kelly et al. 2009). Thus, $\operatorname{PPAR} \alpha$ agonists are under investigation as potential therapies for patients with metabolic and cardiovascular disease (Buse et al. 2005, Henry et al. 2009). Despite this, it is unclear whether activation of individual components of the $\operatorname{PPAR} \alpha$ regulatory circuit provides a benefit to patients with metabolic disease, particularly in the liver. In particular, hepatic PGC-1 $\alpha$ is increased in rodent models of type 2 diabetes mellitus (T2DM; Herzig et al. 2001, Yoon et al. 2001) which may lead to induction of gluconeogenesis and hyperglycemia, while at least two clinical studies have identified a correlation between mutations of the PPARGC1A gene (previously known as the PGC- $1 \alpha$ gene) and insulin resistance or diabetes (Ek et al. 2001, Hara et al. 2002). Overexpression of PGC-1 $\alpha$ in cultures of primary rat skeletal muscle cells induces increased expression of the mammalian tribbles homolog TRB3, an inhibitor of AKT signaling (Mortensen et al. 2006), highlighting the potential of $\mathrm{PGC}-1 \alpha$ to cause insulin resistance. Moreover, PGC-1 $-1-$ mice are protected against high-fat diet induced insulin resistance (Leone et al. 2005). Acute disruption of hepatic PGC-1 expression enhances insulin sensitivity, in part reflecting reduced expression of TRIB3 (Koo et al. 2004). The observation that, in liver, TRIB3 is a target for $\operatorname{PPAR} \alpha$ and that knockdown of hepatic TRIB3 expression improves glucose tolerance, whereas hepatic overexpression of TRIB3 reverses the insulin-sensitive phenotype of PGC-1-deficient mice has led to the suggestion that TRIB3 inhibitors may have a potential role in the treatment of T2DM (Koo et al. 2004). However, more recently, chronic reduction of hepatic PGC- $1 \alpha$ expression has been shown to impair hepatic insulin sensitivity (Estall et al. 2009).

Epigenetic modification, including DNA methylation, represents a molecular mechanism linking environmental events to altered gene expression and the development of disease states, including T2DM (see e.g. (Pembrey et al. 2006)). A recent study undertook a genome-wide promoter analysis of DNA methylation, screening for genes differentially methylated in T2DM, which identified cytosine hypermethylation of PGC- $1 \alpha$ in diabetic subjects (Barres et al. 2009). Hypermethylation of the PGC- $1 \alpha$ promoter was associated with reduced PGC-1 $\alpha$ expression (Barres et al. 2009). Using human myotubes, a link between the DNA methyltransferase (DNMT3B) and acute non-CpG methylation of the PGC-1 $\alpha$ promoter by FA was identified (Barres et al. 2009). The full therapeutic significance of this observation has yet to be established.

Overexpression in liver of the long form of lipin-1 (lipin $1 \beta$, the predominant form in liver; Huffman et al. 2002, Peterfy et al. 2005) increases the expression of PPAR $\alpha$ and PPAR $\alpha$ target genes involved in FA uptake and utilization (Finck et al. 2006). Thus, lipin-1 may be a promising target for therapeutic intervention for metabolic disorders such as fatty liver and resolution of insulin resistance. Lipin-1 is also required for the maintenance of the mature adipocyte phenotype both through its PAP activity in relation to TAG synthesis and via its action to amplify the transcriptional activity of PPAR $\gamma$ and the expression of PPAR $\gamma$ target genes, such as PEPCK and glycerol kinase (Koh et al. 2008). Alterations in lipin-1 function in adipose tissue are therefore likely to impact the efficacy of the TZDs in the treatment of insulin resistance. In addition, the expression of the lipin-1 isoform found in mature adipocytes (lipin-1 $\beta$ ) increases following TZD treatment, which causes weight gain (Yao-Borengasser et al. 2006).

A recent study on nondiabetic Chinese females demonstrated that LPIN1 mRNA levels in abdominal visceral adipose tissue negatively correlated with body mass index, body fat percentage and plasma TAG and leptin levels (Chang et al. 2009). However, no single nucleotide polymorphism of the LPIN1 gene was associated with type 2 diabetes in the population investigated in this study, leading the authors to conclude that the LPIN1 gene was not a major susceptibility gene for T2DM (Chang et al. 2009). Furthermore, the suitability of agonists of lipin-1 as pharmaceutical candidates is confounded given its links with PGC- $1 \alpha$ and its reported ability to induce synthesis of DAG, TAG, and VLDL. It seems likely that the opposing actions of lipin-1 occur in response to different physiological stimuli and therefore further studies are required to establish which lipin-1-directed pathway is dysregulated during the onset of metabolic disease. This will provide important information with respect to development of therapeutic strategies for modulation of this pathway.

Resveratrol, a polyphenol found in red wine, activates SIRTs (Howitz et al. 2003). Treatment of high-fat-fed mice with resveratrol elicits PGC- $1 \alpha$ deacetylation and activcation, opposes weight gain, and enhances insulin sensitivity (Baur et al. 2006, Lagouge et al. 2006). More recently small molecular weight molecules, including SRT1460 and SRT1720, that selectively activate SIRT1 and are 1000-fold more potent activators than (and structurally unrelated to) resveratrol have been identified (Milne et al. 2007). The therapeutic potential of SIRT1 activators to treat 
insulin resistance and diabetes has been examined in vivo in models of T2DM. SRT1720 opposes hyperinsulinemia and the impairment in glucose tolerance introduced by high-fat feeding in mice to an extent similar to that achieved with rosiglitazone (Milne et al. 2007). SRT1720 treatment of Zucker $f a / f a$ rats also impoves glucose and insulin responses during an oral glucose tolerance test (Milne et al. 2007). In addition, the recent identification of four unique lowmolecular-weight inhibitor scaffolds that inhibit the human sirtuins, including SIRT1, by binding reversibly and noncompetitively with respect to both acetyl-lysine and $\mathrm{NAD}^{+}$binding highlights further potential therapeutic tools (Sanders et al. 2009).

The consumption of saturated fat has been linked with the development of a number of disease states, including T2DM, cardiovascular disease and atherosclerosis. Modest SIRT1 overexpression protects against hepatic steatosis and glucose intolerance induced by high-fat feeding (Banks et al. 2008, Pfluger et al. 2008). Hepatic deletion of SIRT1 impairs PPAR $\alpha$ activity, resulting in decreased FA oxidation, and results in hepatic steatosis and inflammation in response to high-fat feeding, leading to the suggestion that therapeutic modulation of SIRT1 activity may be beneficial for the treatment of hepatic diseases as well as obesity-associated metabolic syndrome (Purushotham et al. 2009). Antisense oligonucleotide knockdown of hepatic SIRT1 reduced fasting hyperglycemia by normalizing basal hepatic glucose production, increasing hepatic insulin sensitivity in a rat model of T2DM (streptozotocin injection followed by 4 weeks of fructose and high-fat feeding), which led to the suggestion that novel SIRT1 inhibitors targeted to the liver could prove beneficial in the treatment of T2DM (Erion et al. 2009). Thus, consideration must be given to these potential pitfalls of strategies for mitigation of metabolic disorders involving modulation of SIRT1 activity.

PGC- $1 \beta$ is induced by saturated-fat feeding and results in upregulation of genes involved in FA, TAG and cholesterol synthesis and increases VLDL secretion and accumulation of cholesterol in VLDL, potentially increasing LDL cholesterol (Lin et al. 2005). This has led to the suggestion that upregulation of PGC-1 $\beta$ may link the consumption of saturated fat to hypertriglyceridemia and hypercholesterolemia (Lin et al. 2005). Knockdown of PGC-1 $\beta$ in liver and adipose tissue reverses hepatic insulin resistance induced by fructose feeding and increases whole-body glucose disposal due to increased adipose tissue glucose uptake (Nagai et al. 2009). PGC-1 $\beta$ therefore represents an attractive target for therapeutic intervention in atherosclerosis, insulin resistance and hypertriglyceridemia as well as nonalcoholic fatty liver disease.

\section{Declaration of interest}

The authors declare that there is no conflict of interest that could be perceived as prejudicing the impartiality of the research reported.

\section{Funding}

This study was supported in part by project grants from Diabetes UK (RD08/0003665, RD06/0003424 and RD03/0002725) to MCS and MJH.

\section{References}

Banks AS, Kon N, Knight C, Matsumoto M, Gutierrez-Juarez R, Rossetti L, Gu W \& Accili D 2008 SirT1 gain of function increases energy efficiency and prevents diabetes in mice. Cell Metabolism 8 333-341.

Barres R, Osler ME, Yan J, Rune A, Fritz T, Caidahl K, Krook A \& Zierath JR 2009 Non-CpG methylation of the PGC-1 $\alpha$ promoter through DNMT3B controls mitochondrial density. Cell Metabolism 10 189-198.

Baur JA, Pearson KJ, Price NL, Jamieson HA, Lerin C, Kalra A, Prabhu VV, Allard JS, Lopez-Lluch G, Lewis K et al. 2006 Resveratrol improves health and survival of mice on a high-calorie diet. Nature 444 337-342.

Bihan H, Rouault C, Reach G, Poitout V, Staels B \& Guerre-Millo M 2005 Pancreatic islet response to hyperglycemia is dependent on peroxisome proliferator-activated receptor $\alpha(\operatorname{PPAR} \alpha)$. FEBS Letters 579 2284-2288.

Bordone L, Motta MC, Picard F, Robinson A, Jhala US, Apfeld J, McDonagh T, Lemieux M, McBurney M, Szilvasi A et al. 2006 Sirt1 regulates insulin secretion by repressing UCP2 in pancreatic $\beta$ cells. PLoS Biology 4 e31.

Bou Khalil M, Sundaram M, Zhang HY, Links PH, Raven JF, Manmontri B, Sariahmetoglu M, Tran K, Reue K, Brindley DN et al. 2009 The level and compartmentalization of phosphatidate phosphatase-1 (lipin-1) control the assembly and secretion of hepatic VLDL. Journal of Lipid Research 50 47-58.

Buse JB, Rubin CJ, Frederich R, Viraswami-Appanna K, Lin KC, Montoro R, Shockey G \& Davidson JA 2005 Muraglitazar, a dual $(\alpha / \gamma)$ PPAR activator: a randomized, double-blind, placebo-controlled, 24-week monotherapy trial in adult patients with type 2 diabetes. Clinical Therapeutics 27 1181-1195.

Cao G, Liang Y, Broderick CL, Oldham BA, Beyer TP, Schmidt RJ, Zhang Y, Stayrook KR, Suen C, Otto KA et al. 2003 Antidiabetic action of a liver X receptor agonist mediated by inhibition of hepatic gluconeogenesis. Journal of Biological Chemistry 278 1131-1136.

Cha JY \& Repa JJ 2007 The liver X receptor (LXR) and hepatic lipogenesis. The carbohydrate-response element-binding protein is a target gene of LXR. Journal of Biological Chemistry 282 743-751.

Chang YC, Chang LY, Chang TJ, Jiang YD, Lee KC, Kuo SS, Lee WJ \& Chuang LM 2009 The associations of LPIN1 gene expression in adipose tissue with metabolic phenotypes in the Chinese population. Obesity DOI: $10.1038 /$ oby.2009.198.

Chen G, Liang G, Ou J, Goldstein JL \& Brown MS 2004 Central role for liver $\mathrm{X}$ receptor in insulin-mediated activation of Srebp-1c transcription and stimulation of fatty acid synthesis in liver. PNAS 101 11245-11250.

Dahlman I, Nilsson M, Jiao H, Hoffstedt J, Lindgren CM, Humphreys K, Kere J, Gustafsson JA, Arner P \& Dahlman-Wright K 2006 Liver X receptor gene polymorphisms and adipose tissue expression levels in obesity. Pharmacogenetics and Genomics 16 881-889.

Dalen KT, Ulven SM, Bamberg K, Gustafsson JA \& Nebb HI 2003 Expression of the insulin-responsive glucose transporter GLUT4 in adipocytes is dependent on liver X receptor $\alpha$. Journal of Biological Chemistry 278 48283-48291.

De Souza CT, Gasparetti AL, Pereira-da-Silva M, Araujo EP, Carvalheira JB, Saad MJ, Boschero AC, Carneiro EM \& Velloso LA 2003 Peroxisome proliferator-activated receptor $\gamma$ coactivator-1-dependent uncoupling protein-2 expression in pancreatic islets of rats: a novel pathway for neural control of insulin secretion. Diabetologia 46 1522-1531.

De Souza CT, Araujo EP, Prada PO, Saad MJ, Boschero AC \& Velloso LA 2005 Short-term inhibition of peroxisome proliferator-activated receptor$\gamma$ coactivator- $1 \alpha$ expression reverses diet-induced diabetes mellitus and hepatic steatosis in mice. Diabetologia 48 1860-1871.

Dentin R, Liu Y, Koo SH, Hedrick S, Vargas T, Heredia J, Yates J III \& Montminy M 2007 Insulin modulates gluconeogenesis by inhibition of the coactivator TORC2. Nature 449 366-369. 
Donkor J, Sparks LM, Xie H, Smith SR \& Reue K 2008 Adipose tissue lipin-1 expression is correlated with peroxisome proliferator-activated receptor $\alpha$ gene expression and insulin sensitivity in healthy young men. Journal of Clinical Endocrinology and Metabolism 93 233-239.

Ek J, Andersen G, Urhammer SA, Gaede PH, Drivsholm T, Borch-Johnsen K, Hansen T \& Pedersen O 2001 Mutation analysis of peroxisome proliferatoractivated receptor- $\gamma$ coactivator-1 (PGC-1) and relationships of identified amino acid polymorphisms to type II diabetes mellitus. Diabetologia $\mathbf{4 4}$ 2220-2226.

Erion DM, Yonemitsu S, Nie Y, Nagai Y, Gillum MP, Hsiao JJ, Iwasaki T, Stark R, Weismann D, Yu XX et al. 2009 SirT1 knockdown in liver decreases basal hepatic glucose production and increases hepatic insulin responsiveness in diabetic rats. PNAS 106 11288-11293.

Estall JL, Kahn M, Cooper MP, Fisher FM, Wu MK, Laznik D, Qu L, Cohen DE, Shulman GI \& Spiegelman BM 2009 Sensitivity of lipid metabolism and insulin signaling to genetic alterations in hepatic peroxisome proliferator-activated receptor- $\gamma$ coactivator- $1 \alpha$ expression. Diabetes 58 1499-1508.

Finck BN, Gropler MC, Chen Z, Leone TC, Croce MA, Harris TE, Lawrence JC Jr \& Kelly DP 2006 Lipin 1 is an inducible amplifier of the hepatic PGC-1 $\alpha /$ PPAR $\alpha$ regulatory pathway. Cell Metabolism 4 199-210.

Franckhauser S, Munoz S, Pujol A, Casellas A, Riu E, Otaegui P, Su B \& Bosch F 2002 Increased fatty acid re-esterification by PEPCK overexpression in adipose tissue leads to obesity without insulin resistance. Diabetes 51 624-630.

Frescas D, Valenti L \& Accili D 2005 Nuclear trapping of the forkhead transcription factor FoxO1 via Sirt-dependent deacetylation promotes expression of glucogenetic genes. Journal of Biological Chemistry $\mathbf{2 8 0}$ 20589-20595.

Friedman J 2002 Fat in all the wrong places. Nature 415 268-269.

Gerhart-Hines Z, Rodgers JT, Bare O, Lerin C, Kim SH, Mostoslavsky R, Alt FW, Wu Z \& Puigserver P 2007 Metabolic control of muscle mitochondrial function and fatty acid oxidation through SIRT1/PGC- $1 \alpha$. EMBO Journal 26 1913-1923.

Grimaldi PA 2001 The roles of PPARs in adipocyte differentiation. Progress in Lipid Research 40 269-281.

Guan HP, Ishizuka T, Chui PC, Lehrke M \& Lazar MA 2005 Corepressors selectively control the transcriptional activity of PPAR $\gamma$ in adipocytes. Genes and Development 19 453-461.

Gupta RK, Vatamaniuk MZ, Lee CS, Flaschen RC, Fulmer JT, Matschinsky FM, Duncan SA \& Kaestner KH 2005 The MODY1 gene HNF-4 $\alpha$ regulates selected genes involved in insulin secretion. Journal of Clinical Investigation 115 1006-1015.

Hara K, Tobe K, Okada T, Kadowaki H, Akanuma Y, Ito C, Kimura S \& Kadowaki T 2002 A genetic variation in the PGC-1 gene could confer insulin resistance and susceptibility to type II diabetes. Diabetologia $\mathbf{4 5}$ 740-743.

Henry RR, Lincoff AM, Mudaliar S, Rabbia M, Chognot C \& Herz M 2009 Effect of the dual peroxisome proliferator-activated receptor- $\alpha / \gamma$ agonist aleglitazar on risk of cardiovascular disease in patients with type 2 diabetes (SYNCHRONY): a phase II, randomised, dose-ranging study. Lancet 374 126-135.

Herzig S, Long F, Jhala US, Hedrick S, Quinn R, Bauer A, Rudolph D, Schutz G, Yoon C, Puigserver P et al. 2001 CREB regulates hepatic gluconeogenesis through the coactivator PGC-1. Nature 413 179-183.

Holness MJ \& Sugden MC 2001 Dexamethasone during late gestation exacerbates peripheral insulin resistance and selectively targets glucosesensitive functions in $\beta$ cell and liver. Endocrinology 142 3742-3748.

Holness MJ, Greenwood GK, Smith ND \& Sugden MC 2006 Peroxisome proliferator-activated receptor- $\alpha$ and glucocorticoids interactively regulate insulin secretion during pregnancy. Diabetes 55 3501-3508.

Horton JD, Shimomura I, Brown MS, Hammer RE, Goldstein JL \& Shimano H 1998 Activation of cholesterol synthesis in preference to fatty acid synthesis in liver and adipose tissue of transgenic mice overproducing sterol regulatory element-binding protein-2. Journal of Clinical Investigation $1012331-2339$.
Howitz KT, Bitterman KJ, Cohen HY, Lamming DW, Lavu S, Wood JG, Zipkin RE, Chung P, Kisielewski A, Zhang LL et al. 2003 Small molecule activators of sirtuins extend Saccharomyces cerevisiae lifespan. Nature $\mathbf{4 2 5}$ 191-196.

Huffman TA, Mothe-Satney I \& Lawrence JC Jr 2002 Insulin-stimulated phosphorylation of lipin mediated by the mammalian target of rapamycin. PNAS 99 1047-1052.

Irrcher I, Ljubicic V \& Hood DA 2009 Interactions between ROS and AMP kinase activity in the regulation of PGC- $1 \alpha$ transcription in skeletal muscle cells. American Journal of Physiology. Cell Physiology 296 C116-C123.

Ishimoto K, Nakamura H, Tachibana K, Yamasaki D, Ota A, Hirano KI, Tanaka T, Hamakubo T, Sakai J, Kodama T et al. 2009 Sterol-mediated regulation of human lipin 1 gene expression in hepatoblastoma cells. Journal of Biological Chemistry 284 22195-22205.

Iwasaki H 2009 Impaired PRMT1 activity in the liver and pancreas of type 2 diabetic Goto-Kakizaki rats. Life Sciences 85 161-166.

Juvet LK, Andresen SM, Schuster GU, Dalen KT, Tobin KA, Hollung K, Haugen F, Jacinto S, Ulven SM, Bamberg K et al. 2003 On the role of liver $\mathrm{X}$ receptors in lipid accumulation in adipocytes. Molecular Endocrinology $\mathbf{1 7}$ 172-182.

Kalaany NY, Gauthier KC, Zavacki AM, Mammen PP, Kitazume T, Peterson JA, Horton JD, Garry DJ, Bianco AC \& Mangelsdorf DJ 2005 LXRs regulate the balance between fat storage and oxidation. Cell Metabolism 1 231-244.

Kelly TJ, Lerin C, Haas W, Gygi SP \& Puigserver P 2009 GCN5-mediated transcriptional control of the metabolic coactivator PGC-1 $\beta$ through lysine acetylation. Journal of Biological Chemistry 284 19945-19952.

Knight BL, Patel DD, Humphreys SM, Wiggins D \& Gibbons GF 2003 Inhibition of cholesterol absorption associated with a PPAR $\alpha$-dependent increase in $\mathrm{ABC}$ binding cassette transporter $\mathrm{A} 1$ in mice. Journal of Lipid Research 44 2049-2058.

Koh YK, Lee MY, Kim JW, Kim M, Moon JS, Lee YJ, Ahn YH \& Kim KS 2008 Lipin1 is a key factor for the maturation and maintenance of adipocytes in the regulatory network with CCAAT/enhancer-binding protein $\alpha$ and peroxisome proliferator-activated receptor $\gamma 2$. Journal of Biological Chemistry 283 34896-34906.

Koo SH, Satoh H, Herzig S, Lee CH, Hedrick S, Kulkarni R, Evans RM, Olefsky J \& Montminy M 2004 PGC-1 promotes insulin resistance in liver through PPAR- $\alpha$-dependent induction of TRB-3. Nature Medicine $10530-534$

Koo SH, Flechner L, Qi L, Zhang X, Screaton RA, Jeffries S, Hedrick S, $\mathrm{Xu}$ W, Boussouar F, Brindle P et al. 2005 The CREB coactivator TORC2 is a key regulator of fasting glucose metabolism. Nature $\mathbf{4 3 7}$ 1109-1111.

Krause BR \& Hartman AD 1984 Adipose tissue and cholesterol metabolism. Journal of Lipid Research 25 97-110.

Kubota N, Terauchi Y, Miki H, Tamemoto H, Yamauchi T, Komeda K, Satoh S, Nakano R, Ishii C, Sugiyama T et al. 1999 PPAR $\gamma$ mediates high-fat diet-induced adipocyte hypertrophy and insulin resistance. Molecular Cell 4 597-609.

Laffitte BA, Chao LC, Li J, Walczak R, Hummasti S, Joseph SB, Castrillo A, Wilpitz DC, Mangelsdorf DJ, Collins JL et al. 2003 Activation of liver X receptor improves glucose tolerance through coordinate regulation of glucose metabolism in liver and adipose tissue. PNAS 100 5419-5424.

Lagouge M, Argmann C, Gerhart-Hines Z, Meziane H, Lerin C, Daussin F, Messadeq N, Milne J, Lambert P, Elliott P et al. 2006 Resveratrol improves mitochondrial function and protects against metabolic disease by activating SIRT1 and PGC-1 $\alpha$. Cell 127 1109-1122.

Le Lay S, Krief S, Farnier C, Lefrere I, Le Liepvre X, Bazin R, Ferre P \& Dugail I 2001 Cholesterol, a cell size-dependent signal that regulates glucose metabolism and gene expression in adipocytes. Journal of Biological Chemistry 276 16904-16910.

Le Lay S, Robichon C, Le Liepvre X, Dagher G, Ferre P \& Dugail I 2003 Regulation of ABCA1 expression and cholesterol efflux during adipose differentiation of 3T3-L1 cells. Journal of Lipid Research 44 1499-1507. 
Leone TC, Lehman JJ, Finck BN, Schaeffer PJ, Wende AR, Boudina S, Courtois M, Wozniak DF, Sambandam N, Bernal-Mizrachi C et al. 2005 PGC- $1 \alpha$ deficiency causes multi-system energy metabolic derangements: muscle dysfunction, abnormal weight control and hepatic steatosis. PLoS Biology 3 e101.

Lerin C, Rodgers JT, Kalume DE, Kim SH, Pandey A \& Puigserver P 2006 GCN5 acetyltransferase complex controls glucose metabolism through transcriptional repression of PGC-1 $\alpha$. Cell Metabolism 3 429-438.

Li X, Monks B, Ge Q \& Birnbaum MJ 2007a Akt/PKB regulates hepatic metabolism by directly inhibiting PGC- $1 \alpha$ transcription coactivator. Nature 447 1012-1016.

Li X, Zhang S, Blander G, Tse JG, Krieger M \& Guarente L 2007b SIRT1 deacetylates and positively regulates the nuclear receptor LXR. Molecular Cell 28 91-106.

Lin J, Wu PH, Tarr PT, Lindenberg KS, St-Pierre J, Zhang CY, Mootha VK, Jager S, Vianna CR, Reznick RM et al. 2004 Defects in adaptive energy metabolism with CNS-linked hyperactivity in PGC-1 $\alpha$ null mice. Cell 119 121-135.

Lin J, Yang R, Tarr PT, Wu PH, Handschin C, Li S, Yang W, Pei L, Uldry M, Tontonoz $\mathrm{P}$ et al. 2005 Hyperlipidemic effects of dietary saturated fats mediated through PGC-1 $\beta$ coactivation of SREBP. Cell 120 261-273.

Liu Y, Dentin R, Chen D, Hedrick S, Ravnskjaer K, Schenk S, Milne J, Meyers DJ, Cole P, Yates J III et al. 2008 A fasting inducible switch modulates gluconeogenesis via activator/coactivator exchange. Nature $\mathbf{4 5 6}$ 269-273.

Mandard S, Muller M \& Kersten S 2004 Peroxisome proliferator-activated receptor $\alpha$ target genes. Cellular and Molecular Life Sciences 61 393-416.

Michael LF, Wu Z, Cheatham RB, Puigserver P, Adelmant G, Lehman JJ, Kelly DP \& Spiegelman BM 2001 Restoration of insulin-sensitive glucose transporter (GLUT4) gene expression in muscle cells by the transcriptional coactivator PGC-1. PNAS 98 3820-3825.

Milne JC, Lambert PD, Schenk S, Carney DP, Smith JJ, Gagne DJ, Jin L, Boss O, Perni RB, Vu CB et al. 2007 Small molecule activators of SIRT1 as therapeutics for the treatment of type 2 diabetes. Nature 450 712-716.

Miranda M, Chacon MR, Gomez J, Megia A, Ceperuelo-Mallafre V, Veloso S, Saumoy M, Gallart L, Richart C, Fernandez-Real JM et al. 2007 Human subcutaneous adipose tissue LPIN1 expression in obesity, type 2 diabetes mellitus, and human immunodeficiency virus - associated lipodystrophy syndrome. Metabolism 56 1518-1526.

Mitro N, Mak PA, Vargas L, Godio C, Hampton E, Molteni V, Kreusch A \& Saez E 2007 The nuclear receptor LXR is a glucose sensor. Nature $\mathbf{4 4 5}$ 219-223.

Mortensen OH, Frandsen L, Schjerling P, Nishimura E \& Grunnet N 2006 PGC- $1 \alpha$ and PGC- $1 \beta$ have both similar and distinct effects on myofiber switching toward an oxidative phenotype. American Journal of Physiology. Endocrinology and Metabolism 291 E807-E816.

Moynihan KA, Grimm AA, Plueger MM, Bernal-Mizrachi E, Ford E, Cras-Meneur C, Permutt MA \& Imai S 2005 Increased dosage of mammalian Sir2 in pancreatic $\beta$ cells enhances glucose-stimulated insulin secretion in mice. Cell Metabolism 2 105-117.

Nagai Y, Yonemitsu S, Erion DM, Iwasaki T, Stark R, Weismann D, Dong J, Zhang D, Jurczak MJ, Loffler MG et al. 2009 The role of peroxisome proliferator-activated receptor $\gamma$ coactivator-1 $\beta$ in the pathogenesis of fructose-induced insulin resistance. Cell Metabolism 9 252-264.

Nakae J, Biggs WH III, Kitamura T, Cavenee WK, Wright CV, Arden KC \& Accili D 2002 Regulation of insulin action and pancreatic $\beta$-cell function by mutated alleles of the gene encoding forkhead transcription factor Foxo1. Nature Genetics 32 245-253.

Nielsen LL 2005 Incretin mimetics and DPP-IV inhibitors for the treatment of type 2 diabetes. Drug Discovery Today 10 703-710.

Nolan CJ \& Prentki M 2008 The islet $\beta$-cell: fuel responsive and vulnerable. Trends in Endocrinology and Metabolism 19 285-291.

Park KW, Halperin DS \& Tontonoz P 2008 Before they were fat: adipocyte progenitors. Cell Metabolism 8 454-457.

Patel DD, Knight BL, Wiggins D, Humphreys SM \& Gibbons GF 2001 Disturbances in the normal regulation of SREBP-sensitive genes in PPAR $\boldsymbol{\alpha}$-deficient mice. Journal of Lipid Research 42 328-337.
Pembrey ME, Bygren LO, Kaati G, Edvinsson S, Northstone K, Sjostrom M \& Golding J 2006 Sex-specific, male-line transgenerational responses in humans. European Journal of Human Genetics 14 159-166.

Peterfy M, Phan J \& Reue K 2005 Alternatively spliced lipin isoforms exhibit distinct expression pattern, subcellular localization, and role in adipogenesis. Journal of Biological Chemistry 280 32883-32889.

Pfluger PT, Herranz D, Velasco-Miguel S, Serrano M \& Tschop MH 2008 Sirt1 protects against high-fat diet-induced metabolic damage. PNAS 105 9793-9798.

Phan J \& Reue K 2005 Lipin, a lipodystrophy and obesity gene. Cell Metabolism 1 73-83.

Picard F, Kurtev M, Chung N, Topark-Ngarm A, Senawong T, de Oliveira RM, Leid M, McBurney MW \& Guarente L 2004 Sirt1 promotes fat mobilization in white adipocytes by repressing PPAR- $\gamma$. Nature 429 771-776.

Prestwich TC \& Macdougald OA $2007 \mathrm{Wnt} / \beta$-catenin signaling in adipogenesis and metabolism. Current Opinion in Cell Biology 19 612-617.

Puigserver P \& Spiegelman BM 2003 Peroxisome proliferator-activated receptor- $\gamma$ coactivator $1 \alpha$ (PGC-1 $\alpha$ ): transcriptional coactivator and metabolic regulator. Endocrine Reviews 24 78-90.

Puigserver P, Wu Z, Park CW, Graves R, Wright M \& Spiegelman BM 1998 A cold-inducible coactivator of nuclear receptors linked to adaptive thermogenesis. Cell 92 829-839.

Puigserver P, Rhee J, Lin J, Wu Z, Yoon JC, Zhang CY, Krauss S, Mootha VK, Lowell BB \& Spiegelman BM 2001 Cytokine stimulation of energy expenditure through $\mathrm{p} 38 \mathrm{MAP}$ kinase activation of PPAR $\gamma$ coactivator-1. Molecular Cell 8 971-982.

Puigserver P, Rhee J, Donovan J, Walkey CJ, Yoon JC, Oriente F, Kitamura Y, Altomonte J, Dong H, Accili D et al. 2003 Insulin-regulated hepatic gluconeogenesis through FOXO1-PGC- $1 \alpha$ interaction. Nature $\mathbf{4 2 3}$ 550-555.

Purushotham A, Schug TT, Xu Q, Surapureddi S, Guo X \& Li X 2009 Hepatocyte-specific deletion of SIRT1 alters fatty acid metabolism and results in hepatic steatosis and inflammation. Cell Metabolism 9 327-338.

Ramsey KM, Mills KF, Satoh A \& Imai S 2008 Age-associated loss of Sirt1-mediated enhancement of glucose-stimulated insulin secretion in $\beta$ cell-specific Sirt1-overexpressing (BESTO) mice. Aging Cell 7 78-88.

Repa JJ, Liang G, Ou J, Bashmakov Y, Lobaccaro JM, Shimomura I, Shan B, Brown MS, Goldstein JL \& Mangelsdorf DJ 2000 Regulation of mouse sterol regulatory element-binding protein-1c gene (SREBP-1c) by oxysterol receptors, $\operatorname{LXR} \alpha$ and LXR $\beta$. Genes and Development 14 2819-2830.

Reue K 2009 The lipin family: mutations and metabolism. Current Opinion in Lipidology 20 165-170.

Reue K \& Zhang P 2008 The lipin protein family: dual roles in lipid biosynthesis and gene expression. FEBS Letters $\mathbf{5 8 2}$ 90-96.

Reue K, Xu P, Wang XP \& Slavin BG 2000 Adipose tissue deficiency, glucose intolerance, and increased atherosclerosis result from mutation in the mouse fatty liver dystrophy (fld) gene. Journal of Lipid Research $\mathbf{4 1}$ 1067-1076

Rodgers JT, Lerin C, Haas W, Gygi SP, Spiegelman BM \& Puigserver P 2005 Nutrient control of glucose homeostasis through a complex of PGC- $1 \alpha$ and SIRT1. Nature 434 113-118.

Rodgers JT, Lerin C, Gerhart-Hines Z \& Puigserver P 2008 Metabolic adaptations through the PGC- $1 \alpha$ and SIRT1 pathways. FEBS Letters $\mathbf{5 8 2}$ 46-53.

Rosen ED, Walkey CJ, Puigserver P \& Spiegelman BM 2000 Transcriptional regulation of adipogenesis. Genes and Development 14 1293-1307.

Ryu D, Oh KJ, Jo HY, Hedrick S, Kim YN, Hwang YJ, Park TS, Han JS, Choi CS, Montminy M et al. 2009 TORC2 regulates hepatic insulin signaling via a mammalian phosphatidic acid phosphatase, LIPIN1. Cell Metabolism 9 240-251.

Sanders BD, Jackson B, Brent M, Taylor AM, Dang W, Berger SL, Schreiber SL, Howitz K \& Marmorstein R 2009 Identification and characterization of novel sirtuin inhibitor scaffolds. Bioorganic and Medicinal Chemistry 17 7031-7041. 
Shimano H, Horton JD, Hammer RE, Shimomura I, Brown MS \& Goldstein JL 1996 Overproduction of cholesterol and fatty acids causes massive liver enlargement in transgenic mice expressing truncated SREBP-1a. Journal of Clinical Investigation 98 1575-1584.

Shimano H, Horton JD, Shimomura I, Hammer RE, Brown MS \& Goldstein JL 1997 Isoform 1c of sterol regulatory element binding protein is less active than isoform 1a in livers of transgenic mice and in cultured cells. Journal of Clinical Investigation 99 846-854.

Stulnig TM, Oppermann U, Steffensen KR, Schuster GU \& Gustafsson JA $2002 a$ Liver X receptors downregulate $11 \beta$-hydroxysteroid dehydrogenase type 1 expression and activity. Diabetes $512426-2433$.

Stulnig TM, Steffensen KR, Gao H, Reimers M, Dahlman-Wright K, Schuster GU \& Gustafsson JA $2002 b$ Novel roles of liver X receptors exposed by gene expression profiling in liver and adipose tissue. Molecular Pharmacology 62 1299-1305.

Teyssier C, Ma H, Emter R, Kralli A \& Stallcup MR 2005 Activation of nuclear receptor coactivator PGC- $1 \alpha$ by arginine methylation. Genes and Development 19 1466-1473.

Tiraby C, Tavernier G, Lefort C, Larrouy D, Bouillaud F, Ricquier D \& Langin D 2003 Acquirement of brown fat cell features by human white adipocytes. Journal of Biological Chemistry 278 33370-33376.

Tobin KA, Ulven SM, Schuster GU, Steineger HH, Andresen SM, Gustafsson JA \& Nebb HI 2002 Liver X receptors as insulin-mediating factors in fatty acid and cholesterol biosynthesis. Journal of Biological Chemistry 277 10691-10697.

Vidal-Puig A \& O'Rahilly S 2001 Metabolism. Controlling the glucose factory. Nature 413 125-126.

Wu Z, Rosen ED, Brun R, Hauser S, Adelmant G, Troy AE, McKeon C, Darlington GJ \& Spiegelman BM 1999 Cross-regulation of $\mathrm{C} / \mathrm{EBP} \alpha$ and $\operatorname{PPAR} \gamma$ controls the transcriptional pathway of adipogenesis and insulin sensitivity. Molecular Cell 3 151-158.

Yamagata K, Furuta H, Oda N, Kaisaki PJ, Menzel S, Cox NJ, Fajans SS, Signorini S, Stoffel M \& Bell GI 1996 Mutations in the hepatocyte nuclear factor- $4 \alpha$ gene in maturity-onset diabetes of the young (MODY1). Nature 384 458-460.

Yamashita H, Takenoshita M, Sakurai M, Bruick RK, Henzel WJ, Shillinglaw W, Arnot D \& Uyeda K 2001 A glucose-responsive transcription factor that regulates carbohydrate metabolism in the liver. PNAS 98 9116-9121.
Yang J, Williams RS \& Kelly DP 2009 Bcl3 interacts cooperatively with peroxisome proliferator-activated receptor $\gamma(\operatorname{PPAR} \gamma)$ coactivator $1 \alpha$ to coactivate nuclear receptors estrogen-related receptor $\alpha$ and PPAR $\alpha$. Molecular and Cellular Biology 29 4091-4102.

Yao-Borengasser A, Rasouli N, Varma V, Miles LM, Phanavanh B, Starks TN, Phan J, Spencer HJ III, McGehee RE Jr, Reue K et al. 2006 Lipin expression is attenuated in adipose tissue of insulin-resistant human subjects and increases with peroxisome proliferator-activated receptor $\gamma$ activation. Diabetes 55 2811-2818.

Ye JM, Doyle PJ, Iglesias MA, Watson DG, Cooney GJ \& Kraegen EW 2001 Peroxisome proliferator-activated receptor (PPAR) $-\alpha$ activation lowers muscle lipids and improves insulin sensitivity in high fat-fed rats: comparison with PPAR $-\gamma$ activation. Diabetes 50 411-417.

Yoon JC, Puigserver P, Chen G, Donovan J, Wu Z, Rhee J, Adelmant G, Stafford J, Kahn CR, Granner DK et al. 2001 Control of hepatic gluconeogenesis through the transcriptional coactivator PGC-1. Nature 413 131-138.

Yoon JC, Xu G, Deeney JT, Yang SN, Rhee J, Puigserver P, Levens AR, Yang R, Zhang CY, Lowell BB et al. 2003 Suppression of $\beta$ cell energy metabolism and insulin release by PGC-1 $\alpha$. Developmental Cell 5 73-83.

Yoshikawa T, Ide T, Shimano H, Yahagi N, Amemiya-Kudo M, Matsuzaka T, Yatoh S, Kitamine T, Okazaki H, Tamura Y et al. 2003 Cross-talk between peroxisome proliferator-activated receptor (PPAR) $\alpha$ and liver $\mathrm{X}$ receptor (LXR) in nutritional regulation of fatty acid metabolism. I. PPARs suppress sterol regulatory element binding protein-1c promoter through inhibition of LXR signaling. Molecular Endocrinology 17 1240-1254.

Zhang P, Liu C, Zhang C, Zhang Y, Shen P, Zhang J \& Zhang CY 2005 Free fatty acids increase PGC- $1 \alpha$ expression in isolated rat islets. FEBS Letters 579 1446-1452.

Zhang P, O’Loughlin L, Brindley DN \& Reue K 2008 Regulation of lipin-1 gene expression by glucocorticoids during adipogenesis. Journal of Lipid Research 49 1519-1528.

Received in final form 16 September 2009

Accepted 21 September 2009

Made available online as an Accepted Preprint 21 September 2009 